\title{
Micro-Mobility Infrastructure for Redefining Urban Mobility
}

\author{
Bhagyalaxmi Madapur $^{1 *}$, Shilpa Madangopal ${ }^{2}$ and M. N. Chandrashekar ${ }^{3}$ \\ ${ }^{1}$ Tenure Associate Professor, SJB School of Architecture \& Planning, Bangalore, India \\ ${ }^{2}$ Professor, SJB School of Architecture \& Planning, Bangalore, India \\ ${ }^{3}$ Dean \& Professor, SJB School of Architecture \& Planning, Bangalore, India
}

\begin{tabular}{|c|c|}
\hline ARTICLE INFO & ABSTRACT \\
\hline $\begin{array}{l}\text { Keywords: } \\
\text { Urban mobility } \\
\text { Micro-mobility } \\
\text { Rapid mass } \\
\text { transportation system } \\
\text { First and last mile } \\
\text { connectivity } \\
\text { Accessibility }\end{array}$ & $\begin{array}{l}\text { As the cities grow and their population increase, there is an } \\
\text { intensifying claim for primary components such as housing, } \\
\text { transportation, utility services, water supply, etc. Integrated and } \\
\text { inclusive urban transportation infrastructure addresses dual } \\
\text { purposes - mobility and access to various urban facilities. Urban } \\
\text { mobility is no longer only about movement of people in urban areas. } \\
\text { In the current milieu of increased preferences for personal motorised } \\
\text { transport over public transport, there is a need to redefine and } \\
\text { restructure urban mobility through planned integrated Rapid Mass } \\
\text { Transit (RMT) hubs while harnessing the ICT (Information and } \\
\text { Communication Technology) enabled services to unambiguously } \\
\text { offer diverse mobility choices for providing inclusive and accessible } \\
\text { (spatially and socio-economically) urban spaces. Against this } \\
\text { background, this research paper through a case example attempts to } \\
\text { understand and analyse the major trends that are deciding the modes } \\
\text { of urban mobility with a focus on micro-mobility infrastructure } \\
\text { which is a vital component in addressing the first and last mile } \\
\text { connectivity for the efficient usage of rapid mass transit system. } \\
\text { Further, key strategies are proposed to augment the planning and } \\
\text { implementation of micro-mobility options to improve and redefine } \\
\text { the urban mobility. }\end{array}$ \\
\hline
\end{tabular}

\section{Introduction}

As the cities grow and their population increase, there is an escalating demand for primary components such as housing, transportation, utility services, water supply, etc. Integrated and inclusive urban transportation infrastructure addresses dual purposes - mobility and access to various urban facilities. A well planned urban transportation system is predominantly based on the urban form and thus has larger impact on the inhabitant's preferences for commuting modes. On the other hand, unplanned, uncoordinated and unregulated public transportation services coupled with inadequacies with regard to crucial first and last mile connectivity have been fuelling the urban dweller's preferences for private motorised transportation over public mode. This is unjustifiable as it adds to the congestion, degradation of physical environment, resource consumption, increasing commuting cost and time, etc. Hence urban mobility is no longer only about movement of people in urban areas. All these aspects are leading to the need for redefining the urban mobility. Redefined and restructured urban mobility specifically offers diverse mobility choices while providing inclusive and accessible (spatially and socioeconomically) urban spaces. In this context, integrated Rapid Mass Transit (RMT) Hubs need to be planned along with harnessing the ICT (Information and Communication Technology) enabled services in order to provide environmentally as well as socio-economically balanced RMT options for urban dwellers.

* Corresponding Author E-Mail Address: bhagya.chandgude@gmail.com 


\section{Indian Metropolitan Cities}

Although, rapidly increasing urban agglomerations of most of the Indian metropolitan cities are contributing to the economic growth, the phenomenon is paradoxically presenting numerous challenges with regard to the urban infrastructure services especially the transportation and mobility systems. Unplanned and unstructured urban sprawl coupled with inefficient public transportation systems are contributing for the use of personal motorised transportation which further complicates the already aggravated situation.

\subsection{Favouring the Minority and Marginalizing the Majority}

Among those 140 million people who commute for work/education, etc., the distances tend to be shorter. Indian census data highlights that, 1/3 commute on foot. Another $10 \%$ use bicycles and $16 \%$ travel by bus while $18 \%$ use two-wheelers. More people prefer auto rickshaws or taxis including shared to work than private four - wheelers. Over fifth of secondary and tertiary sector employees commute to work on foot, followed by commutes by cycle, two-wheelers and bus. Fewer than 3\% take cars or shared vans and over half travel less than 5KM. Urban transportation planning in most cities does not take into account the realities of Indian commuting.

In majority of Indian mega cites, walking is the most common mode of commuting as short as well as medium distance trips constitutes the majority of urban trips. For commutes up to $10 \mathrm{KM}$, walking is the most common means of transport, but as distances increase, people prefer taking two-wheelers and buses. This pattern is significantly different for women who commute majorly on foot up to 10KM followed by buses (Refer Figure 1).

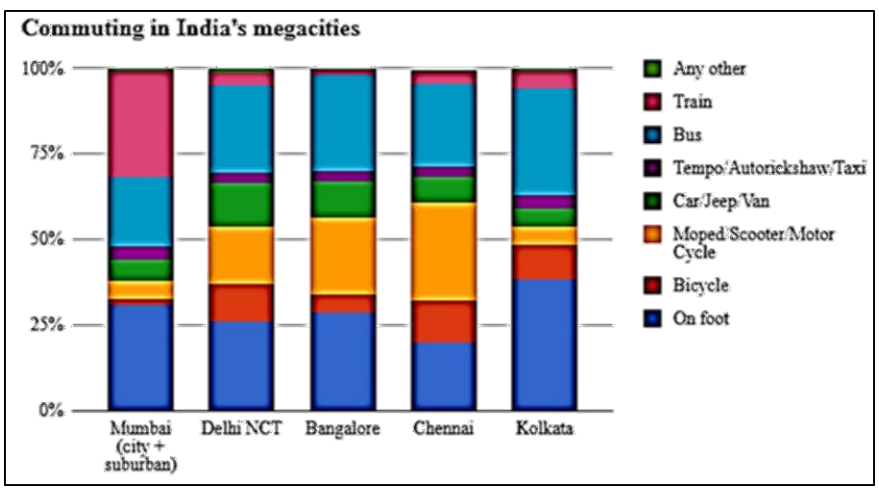

Figure 1. Percentages of different modes of commuting in Indian megacities (Source: Office of the Registrar General of India; updated April 2019)

Despite the fact that the majority of the people walk to work (additionally all public transport trips include walking) and meagre percentage of people use private vehicles, almost all transportation infrastructure investments in the city are made for this minority.

\subsection{Commuting Time Budget}

Accessibility in the urban fabric can be defined as the number of valued destinations that inhabitants can easily reach within their daily "commuting time budget. By and large, commuting time budget has reached a steady state across all the cities of the world. Hence increasing access relies on comprehensive mobility infrastructure which in turn drives socio-economic productivity efficiently. Despite the increasing levels of urban mobility in Indian cities, access to places, activities and services is becoming increasingly difficult in terms of time, conveniences and cost.

\subsection{Variations in the Preferences for Commuting Modes}

Data collated from different sources express that long-distance commuting is still the norm with $20 \%$ of commuters globally and $25 \%$ in India commuting over 90 minutes every day despite of the progress 
in increasing flexible working practices. Such longer commutes harm social well-being and psychological health while lowering the quality of urban life. Preferences for various modes of commute are primarily affected by the location characteristics such as distance and socio-economic factors (age, gender, purpose, occupational pattern, etc.) of the inhabitants. By and large, people prefer to walk if the destination lies within $1.0 \mathrm{Km}$. For distances up to $5.0 \mathrm{KM}$, cycling/two/ auto rickshaws/taxi are preferred based on the age/distance/style of commute, etc. Various modes of public transport are ideal for distances beyond 5.0KM. People would favour public transport over private if these options are structured well and made widely accessible.

\subsection{First and Last Mile Connectivity (FMC and LMC)}

While rapid mass transit is the most efficient means of moving large number of people over long distances, the first and last mile connectivity (FMC and LMC) to get people to and from transit remains a perennial difficulty. If people lack a convenient, affordable way to get on a mass transit, they are most likely to opt for personal transportation contributing to the gridlock. The gap between the level of mass transit service and the needs of the community can create transit deserts - areas with transit dependent community that lack adequate public transit services (Refer Figure 2).

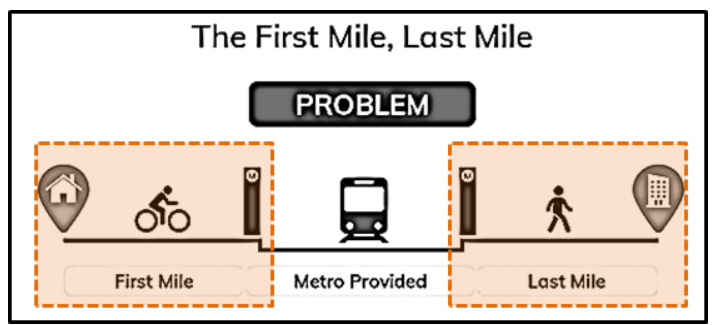

Figure 2. Transit deserts (Source: Representational picture edited by authors)

\subsection{Micro-mobility to better address FMC and LMC}

In recent years, micro-mobility is emerging as a potential solution to the growing demands on the existing transportation network. It offers attractive solutions for first and last mile connectivity and aids in mitigating transit deserts. Possibly the most apt way to think about what micro-mobility is and can be is in relation to existing infrastructure. Several studies highlight the fact that conducive and cohesive public transport network supported by greener micro-mobility modes (active transport) promotes active public health as well. Micromobility options based on green means and renewable energy form the significant part of the micro-mobility elements (Refer Figure 3). Major benefits of micro-mobility options are better connectivity to MRTS, reduced usage of personal motorized vehicles and lower levels of GHG (greenhouse gas emissions).
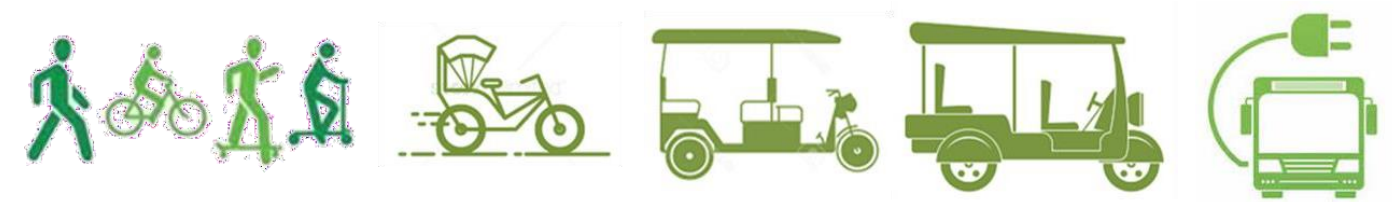

Figure 3. Greener means of micro-mobility options (Source: Google.com and edited by authors)

Several micro-mobility options (such as safe pedestrian infrastructure, bicycles, public as well as private feeder services, auto rickshaws, e-scooters (docked and dock less), e-rickshaws, shared e-bikes and ride hailing taxis, etc.) can help leverage the benefits of mass rapid transportation system by providing first and last mile connectivity while significantly reducing the physical footprint needed to move people over relatively short distances. Different micromobility modes are emerging as a true potential solution for urban mobility, enabled by advances in GPS tracking, connectivity, mobile payments, battery cost \& longevity and the growing ubiquity of smartphones. Micro-mobility options can substantially serve the various 
locations dominated by short trips such as public transit nodes, educational and corporate campuses, military bases, etc. Apart from urban mobility, micro-mobility can improve accessibility to employment, education and health care when they are targeted for the areas more than 500 meters from public transport.

\section{Bangalore Metropolitan City, India}

In the past two decades, Bangalore, the capital city of Karnataka state and Silicon Valley of India has morphed into metropolitan agglomeration with $90 \%$ of Bangaloreans living in urban district with the total built up area increasing by $600 \%$. This phenomenal growth is due to the diverse developments and investments in both public and private sectors (Refer Figure 4).

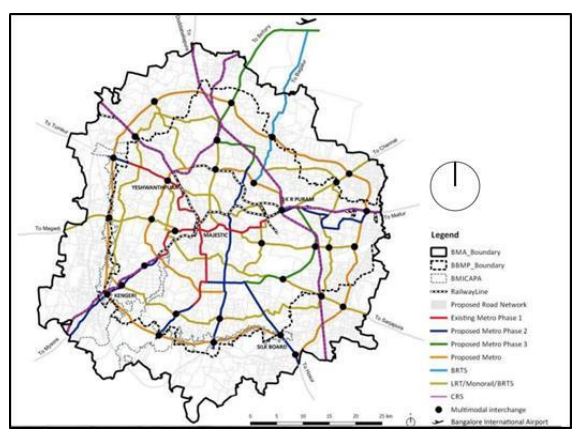

Figure 4. Bangalore metropolitan area showing public transport network (Source: Bangalore Development Authority (BDA), Bangalore)

Currently, Bangalore metropolitan area is served by three major modes of transportation which operate independently resulting in uncoordinated and non-integrated service pattern of public transport system resulting in poor performance, irrational usage of public resources and increasing usage of private motorised transportation subsequently causing negative socioeconomic consequences (Refer Table 1).

Table 1.

Three major modes of Public Transport serving Bangalore metropolitan area

\begin{tabular}{|c|c|c|}
\hline Sl. No. & Mode of transport & Remarks \\
\hline 1 & Bus Transit System & $\begin{array}{l}\text { Provided by Bangalore Metropolitan Transport Corporation } \\
\text { (BMTC). 40,000 } \\
\text { buses carry } 4 \text { million commuters running over } 1 \text { million } \\
\text { kilometres per day. }\end{array}$ \\
\hline 2 & $\begin{array}{l}\text { Rapid Transit System } \\
\text { (Metro rail system) }\end{array}$ & $\begin{array}{l}\text { Provided by Bangalore Metro Rail Corporation Limited } \\
\text { (BMRCL). The carrying capacity of a single metro line is } \\
40,000 \text { for a three coach with a } \\
\text { frequency of } 1.5 \text { minutes assuming the standing density of } 8 \\
\text { people per SqM. }\end{array}$ \\
\hline 3 & $\begin{array}{l}\text { Para Transit (public feeder bus } \\
\text { services, auto rickshaws and taxis) }\end{array}$ & $\begin{array}{l}\text { Provided by both BMTC (feeder bus services limited to } \\
\text { certain areas) and private owners (dedicated private company } \\
\text { bus services, auto rickshaws and } \\
\text { taxis) not having any fixed schedule or routes. }\end{array}$ \\
\hline
\end{tabular}

Source: Information collated from various government transportation authorities

\subsection{First and Last Mile Connectivity in Bangalore Metropolitan Area}

Rapidly changing urban-industrial landscape of Bangalore since the liberalization of India's economy is not only impacting the urban form but also causing uneven growth patterns leading to socio-economic polarization. This is reflected in the changing commuting patterns and pretences of the inhabitants. It is observed from data analysis that, walking and cycling are the most preferred modes for negotiating the initial and final leg of the commute (Refer Table 2). 
Hence, the immediate requirement is to restructure the existing and future mobility options for an effective multimodal MRTS for efficient (in terms of environmentally conscious, planned, coordinated FMC and LMC, socio-economic accessibility,) urban mobility.

Table2.

FMC and LMC percentages for the origin and destinations

\begin{tabular}{lllll}
\hline Sl. No. & \multicolumn{2}{l}{ LMC from origin to MRT station } & \multicolumn{2}{l}{ LMC from destination to MRT station } \\
\hline 1 & Feeder bus & $5 \%$ & Feeder bus & $5 \%$ \\
2 & Rickshaw & $20 \%$ & Rickshaw & $15 \%$ \\
3 & Two wheeler & $20 \%$ & Two wheeler & $20 \%$ \\
4 & Walking / Cycling & $55 \%$ & Walking / Cycling & $60 \%$ \\
\hline \multicolumn{5}{l}{ Source: } \\
Information collated from various & government transportation authorities
\end{tabular}

The following sections of the paper attempts to analyse and address the above discussed crucial components through a case example of Hebbal area located in Bangalore city, India.

\section{Hebbal Area - Contextual Setting}

Hebbal area is located on the northern side of Bangalore city and was once symbolic of the extent of the northern limit of the city (Refer Figure 5). Owing to its strategic location connecting north-south and east-west zones of the city, it is now one of the rapidly growing suburb of Bangalore with several real estate developments fuelled by diverse set of transportation infrastructure projects (Refer Figure $6 \& 7$ ). The area gets its name from the lake named Hebbal located here. This lake covering an area of around 150 acres is one of the three famous lakes created in 1537 by the founder of Bangalore, Kempegowda. It was constructed by damming the natural valley systems through the construction of bunds. The lake is within the chosen Hebbal study area precinct.

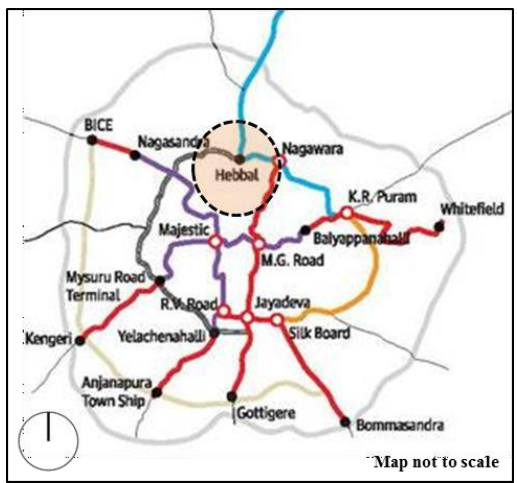

Figure 5. Location of Hebbal area in Bangalore metropolitan area (Source: BMRCL, Bangalore)

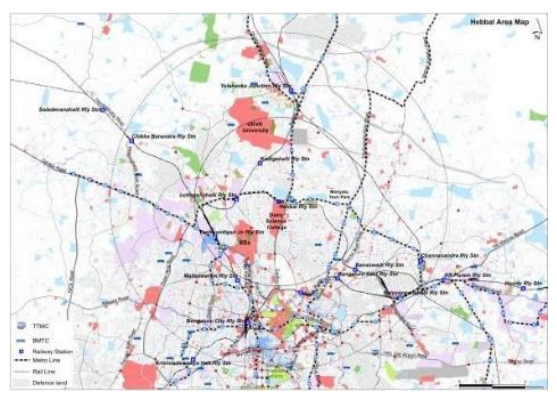

Figure 6. Extent of Hebbal constituency (Source: BDA, Bangalore \& Google maps)

Several arterial roads and state highways leading to north intersect at Hebbal flyover junction (Refer Figure 8). As the city authorities have not considered various crucial aspects of the area and mounting vehicular traffic, the flyover has turned into a bottle-neck for the traffic bound towards north-south and 
east-west. Unregulated mixed vehicular traffic bound to different destinations is choking the main arteries as well as access points leading to congestion, heavy levels of pollution, unsafe atmosphere for pedestrians and unregulated informal commercial activities, etc. (Refer Figure 9).

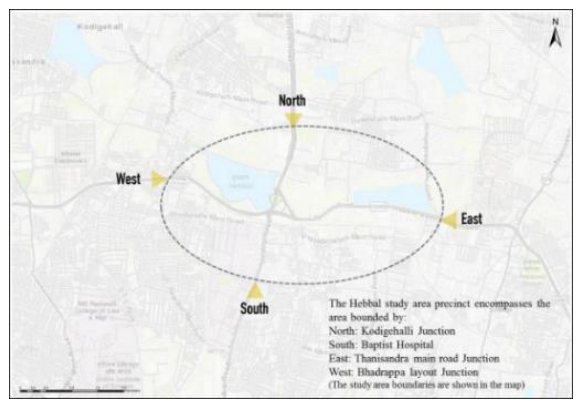

Figure 7. Extent of Hebbal study area precinct (Source: Edited by authors from different sources)

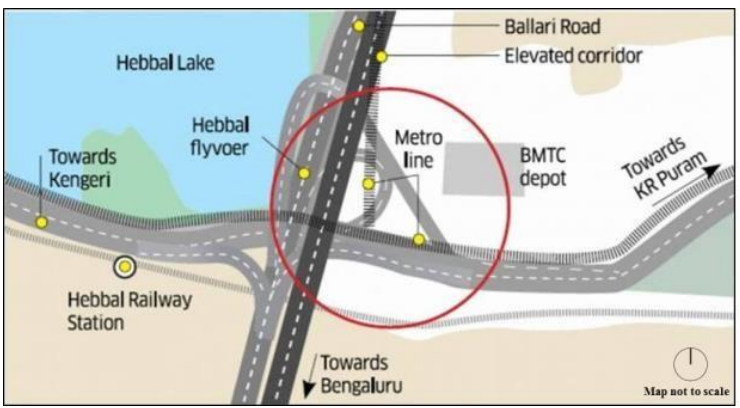

Figure 8. Hebbal flyover junction (Source: Edited by authors from different sources)

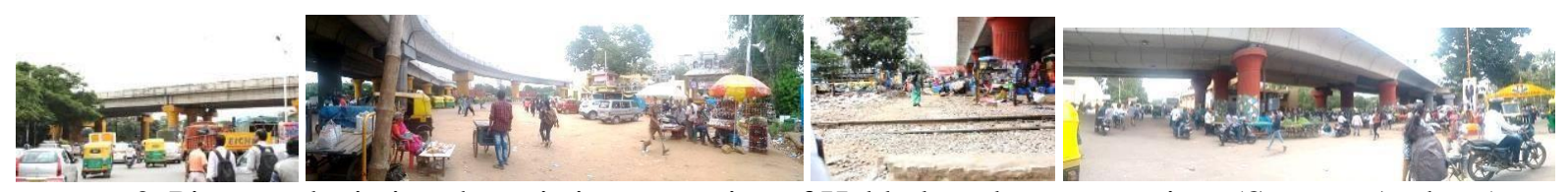

Figure 9. Pictures depicting the existing scenarios of Hebbal study area precinct (Source: Authors)

\subsection{Hebbal Study Area Precinct - Ongoing transportation initiatives}

A number of projects are proposed projects are proposed at the junction. Currently, several departments have taken up initiatives to develop the Hebbal junction (Refer Figure 10). While different transport agencies of the city are gearing up to provide connectivity to this busy junction, there is apprehension if all of them can work in tandem.

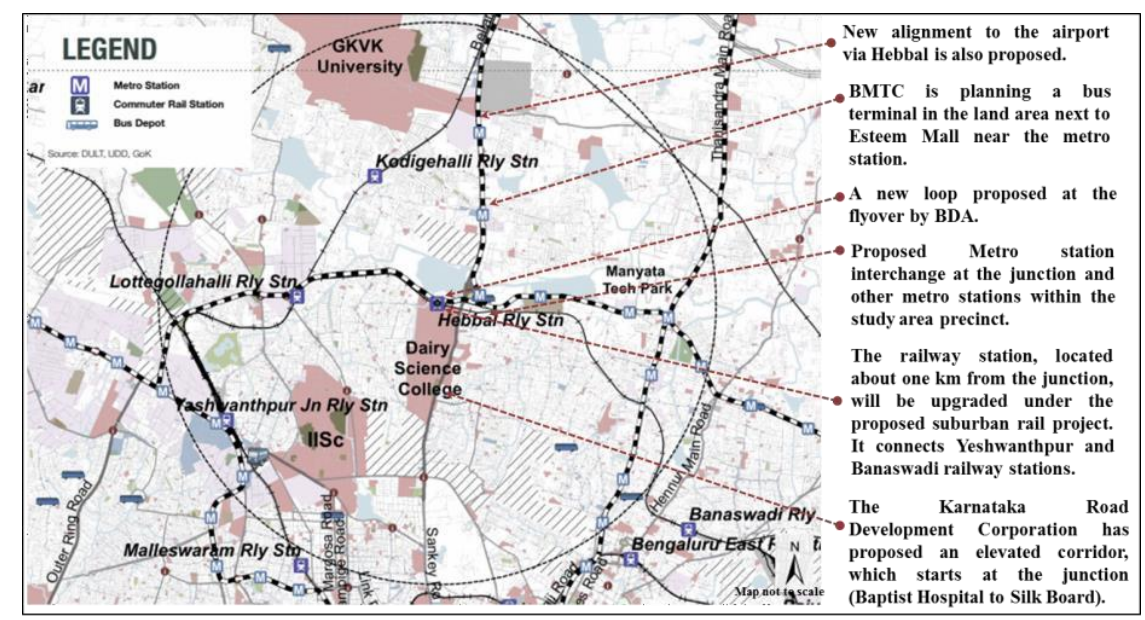

Figure 10. Upcoming transportation initiatives at Hebbal study area precinct (Source: Compiled by authors from various sources) 


\subsection{Hebbal Study Area Precinct - Analysis and Inferences}

Hebbal Study Area Precinct has been analysed under different parameters to understand the impact on the mobility choices and quality of commuting as explained in the following sub headings (Refer Figure 11).

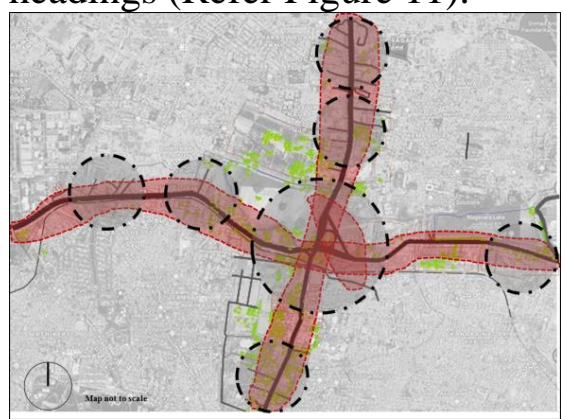

Figure 11. Analysis- Hebbal study area precinct (Source: Authors)

\subsubsection{Low quality urban realm - Uninviting and confusing access-exit points}

The key access-exit points are overpowered by heavy infrastructure and vehicular traffic. Due to the absence of safe pedestrian infrastructure, pedestrians are often put in absurd situations either stranded at intersections or forced to take inconvenient detours or at worst crossing illegally exposing themselves to danger.

\subsubsection{The fine grain fabric}

The fine grain fabric of street networks represents a great potential of diverse experiences and flexible route options when moving around in the precinct. However, these often reflects sense of a maze where one can get lost. In addition to lack of legible street signs, the streets suffer from severe congestion involving both large numbers of vehicular \& pedestrian traffic contributing to the lack of orientation (poor way finding and also perceived notion of unsafe pedestrian environment.

\subsubsection{Traffic dominated pedestrian environment}

Vehicular oriented streets generate unsafe pedestrian conditions with frequent traffic barriers $\&$ pedestrian islands. Also pedestrians have to put up with traffic dominated walking environment intensely polluted with a high noise levels.

\subsubsection{Walkability}

Pedestrians face harsh traffic conditions narrating the story of a city that through the years has prioritised vehicular traffic over pedestrians.

\subsubsection{Intrusive driving and parking}

Intrusive driving and parking dominate the narrow streets resulting in severe congestions in several streets, especially the fine grain structure of surrounding ru-urban areas.

\subsubsection{Indistinct Pedestrian Networks}

Hebbal study area precinct has potential in the form of an abundance of fine grain structures providing good urban experiences and numerous route options. But overall legible coherent pedestrian networks are evidentially absent.

\subsubsection{Missing links, weak and less accessible connections}

Several secondary and tertiary routes link to primary arteries connecting different destinations while facilitating the moment of pedestrians during both day and night. However, a continued high focus on the streets as transit corridors overpowers the retaining dimension of the street 
in turn affecting the larger network.

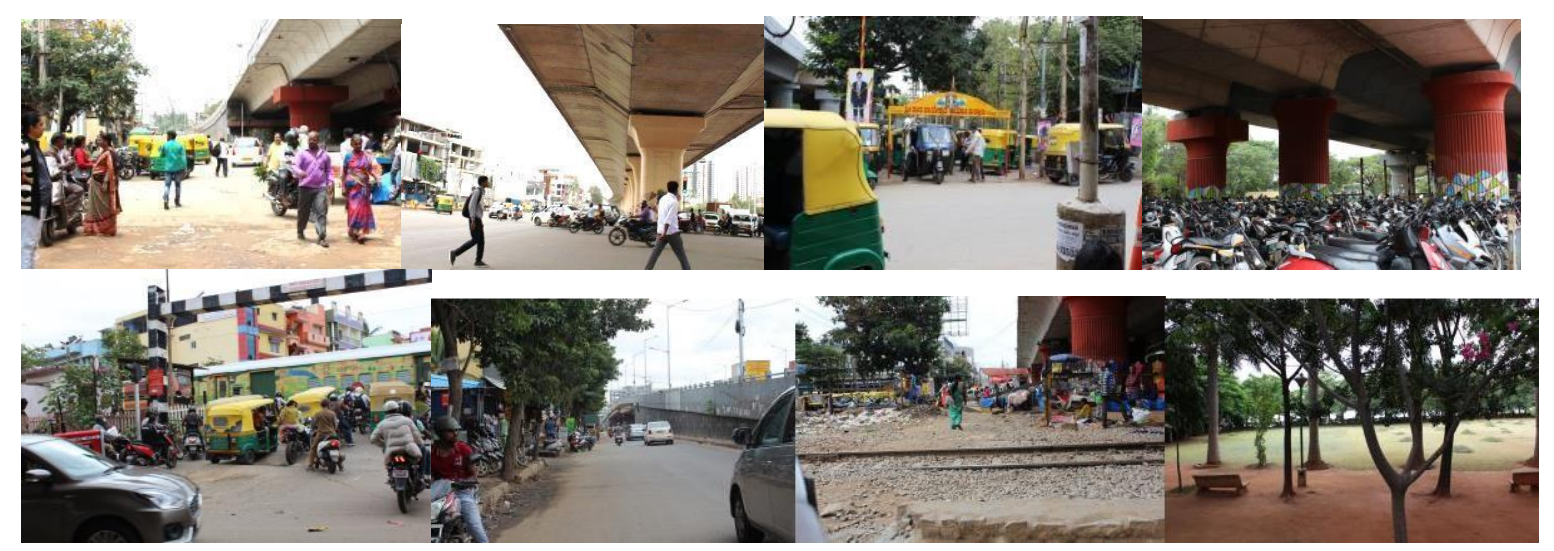

Figure 12. Pictures representing analysis parameters considered for Hebbal study area precinct (Source: Authors)

The following table summarizes the various potentials and challenges of the study area precinct (Refer Table 3).

Table 3.

Hebbal Study Area Precinct - Potentials and Challenges

\begin{tabular}{|c|c|c|}
\hline SI. No. & Potentials & Challenges \\
\hline 1 & $\begin{array}{l}\text { A portal connecting North-South and East- } \\
\text { West zones of the city providing a fertile } \\
\text { ground for the adoption of safe and reliable } \\
\text { urban mobility options. } \\
\text { Owing to the strategic location, Hebbal could } \\
\text { become a multi-modal transportation hub } \\
\text { while leveraging numerous benefits to } \\
\text { commuters of different profiles. }\end{array}$ & $\begin{array}{l}\text { Vibrant existence of sensitive ecology, intriguing } \\
\text { urban structure and socio-economic demographics } \\
\text { can be potentially } \\
\text { used to create unique urban identity while } \\
\text { augmenting the urban experiences and quality of life. } \\
\text { Intrusive urban infrastructure and uncoordinated } \\
\text { urban elements have been entailing a degradation of } \\
\text { the visual environment instigating illegibility, } \\
\text { neglect as well as decay. } \\
\text { Major identities (lake, \& temple) are being } \\
\text { marginalised under the development pressure. }\end{array}$ \\
\hline 3 & $\begin{array}{l}\text { Vibrant existence of sensitive ecology, } \\
\text { intriguing urban structure and socio-economic } \\
\text { demographics can be potentially used to } \\
\text { create unique urban identity while } \\
\text { augmenting the urban experiences and quality } \\
\text { of } \\
\text { life. }\end{array}$ & \\
\hline
\end{tabular}

Source: Authors

\subsection{Strategies for Augmenting Micro-Mobility to Existing and Proposed Mass Transit Facilities \\ Analysis of the various parameters and potentials of the study area precinct highlight the need for the provision of viable combinations of different micro-mobility options with change in the commuting distances (Refer Figure 13).}




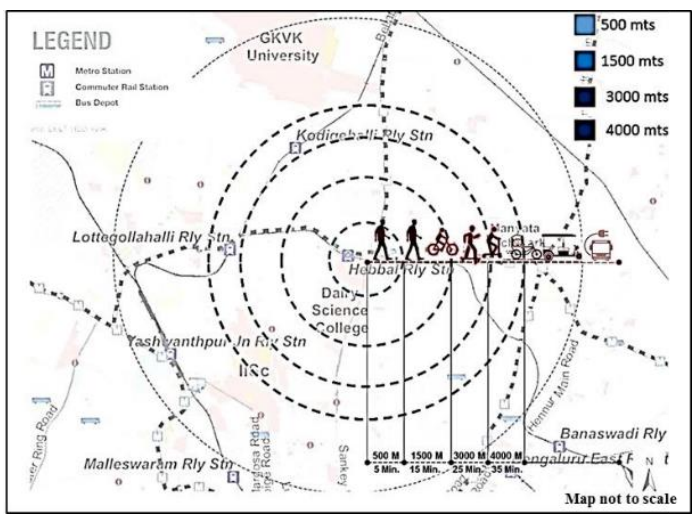

Figure 13. Viable combinations of different micro-mobility options with regard to commuting distances (Source: Authors)

\subsection{NMT (Non-motorized Transport) Nodes}

Based on the analysis of the viability of the adoption of micro-mobility options, NMT (Nonmotorized Transport) Nodes at various scales are proposed for optimum utilization of the existing as well as proposed transportation resources to develop efficient feeder connections in the Hebbal study area precinct while providing the vital first and last mile connectivity. The major implication of these NMT nodes is that they are immediately implementable with minimum investment along with the existing/proposed infrastructure and can permeate through the fabric of the area / neighbourhood with reduced environment pollution /carbon footprint (greener commuting).

Key principles supporting NMT nodes are:

\subsubsection{Safety, Efficiency, Reliability, Preference and Adaptability}

Proposed NMT nodes at different functional levels cater to different micro-mobility options within the short and medium range distances while suiting most types of commuting choices, backgrounds and most importantly budgets. These attributes offer numerous choices to the commuters to have safe, efficient and reliable commute. Preference, adaptability and transition would be convenient as the numerous choices are within the existing movement networks.

\subsubsection{Implementation and Sustainability}

The major implication of these NMT nodes is that they are immediately implementable with minimum investment along with the existing/ proposed infrastructure and can permeate through the fabric of the area / neighborhood with reduced environment pollution /carbon footprint (greener commuting). Public transport has to be integrated into micro-mobility networks through NMT nodes. These NMT nodes provide the following facilities and advantages:

- Shuttle service pod among metro stations, major bus stops, transit nodes, etc. with integrated ticketing systems.

- Better accessibility and connectivity of footpaths/cycle paths with transit stops augmenting safe and faster commuting.

- Pedestrian /cycle facilities like secure parking, information regarding bus schedules / routes shall be developed using ICT interface.

- NMT nodes act as counters for small scale visitor / tourist information center, renting bicycles

- / electric vehicles, various types of ticket booking, utility bill payments, etc. 
- Small scale conveniences / amenities to foster community interactions crafting public space

- Temporal Pedestrianization Strategy can be used during special occasions and can be controlled through formal traffic orders.

\subsubsection{Different types of NMT Nodes}

Based on the analysis of viable combinations of different micro-mobility options with change in the commuting distances, NMT Nodes at various scales are proposed as mentioned below (Refer Figures 14 \&15):

ZONAL NMT NODES - Zonal NMT nodes serve at the different clusters of a ward and connect to other zonal NMT nodes. These nodes can be strategically located at Metro stations, Bus depots, TTMCs. intermodal hubs, etc. Areas below the Metro columns \& flyover, leftover areas resulting from utilitarian infrastructure, etc. can be efficiently used to locate zonal NMT nodes.

LOCAL NMT NODES - Local NMT nodes connect to Zonal NMT nodes while interlinking various neighbourhood NMT nodes. These nodes can be located major street intersections, bus stops, auto rickshaw /taxi stands, local utility facilities, etc.

NEIGHBOURHOOD NMT NODES - Neighbourhood NMT nodes form crucial links to inner areas of the study precinct and cater to the vital first and last mile connectivity. These nodes are located close to neighbourhood clusters, important community facilities, street intersections, bus stops, auto rickshaw /taxi stands, etc.
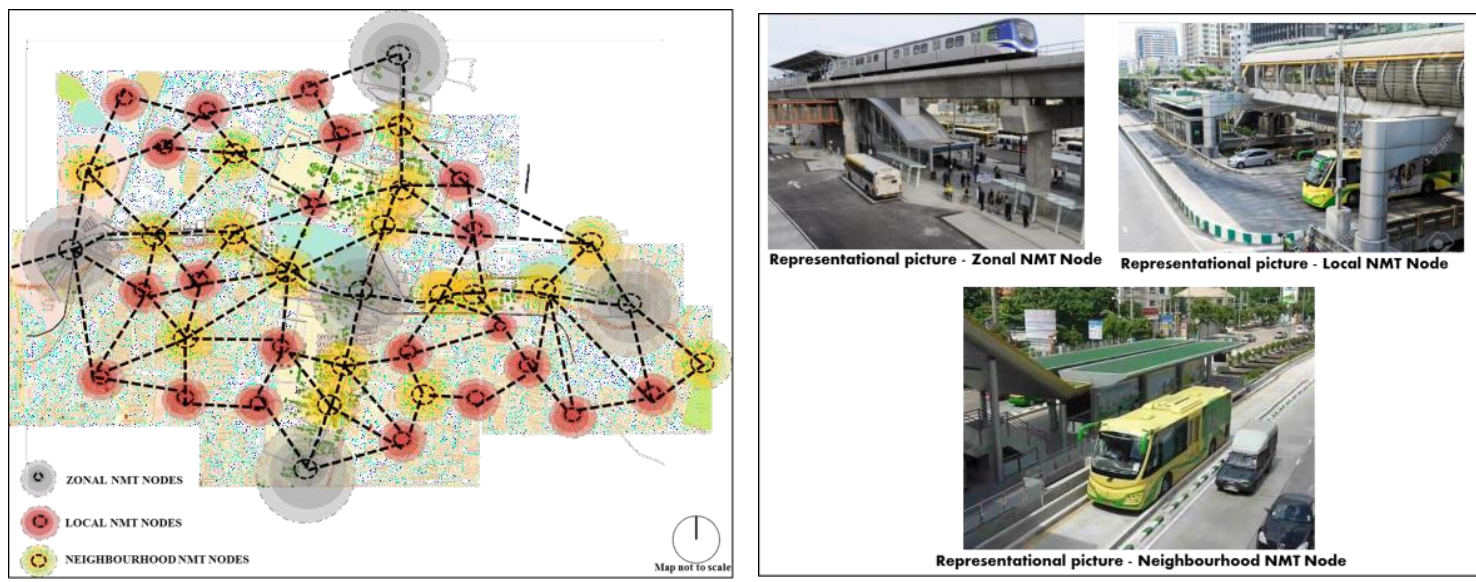

Figure $14 \& 15$ : Location of different types of NMT nodes in the study area precinct \& representational pictures (Source: Authors)

\subsubsection{Conceptual Key Layout of NMT Nodes}

The conceptual key layout of major spaces of NMT nodes are as mentioned below (Refer Figure 16):

- Decision spaces: Areas prioritising commuter's decisions with regard to commuting. Includes integrated ticketing kiosks, parking/drop off/pick up facilities for various micromobility modes.

- Movement spaces: Areas specially reserved for commuter's movement (boarding / alighting to public transport) and various elements related to physical-digital branding / advertising / information boards can be located adjacent to these spaces.

- Opportunity spaces: These spaces are located in the interchange zones or overlapping areas between decision spaces and movement spaces and present numerous opportunities for socio-economic activities. 


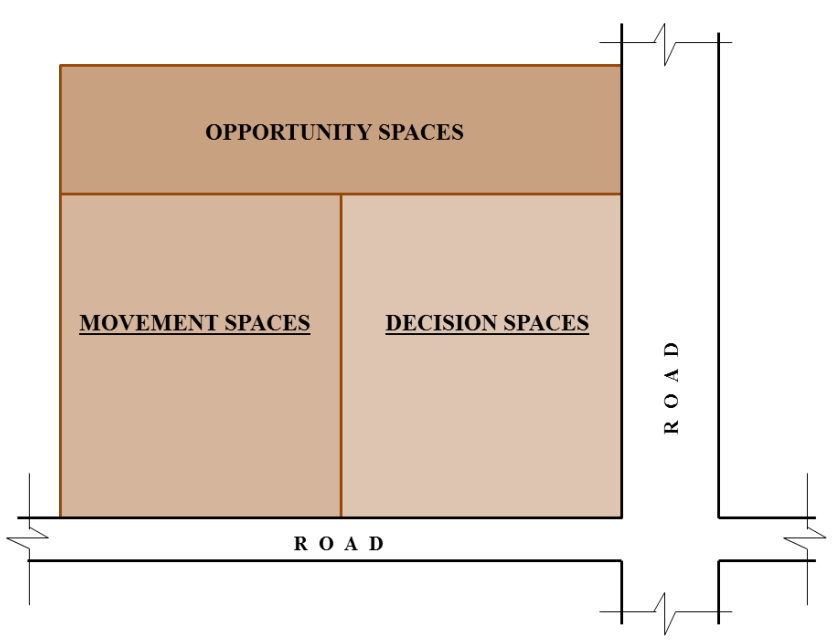

Figure 16. Conceptual key layout of NMT nodes (Source: Authors)

\subsubsection{Key Attributes Supporting NMT Nodes}

The strategic locations and optimum sizes of all the three typologies of NMT nodes can be determined based on the key attributes as described below (Refer Figure 17):

Parameters for Strategic location and optimum sizes:

- Primary functional level of the node (zonal / local / neighbourhood).

- Existing infrastructure and utility facilities mapped through various authorities.

- Community needs and demands collated through primary surveys to address the critical socio- economic issues.

- Minimum and maximum sizes need to be formulated based on the chosen location, user numbers and existing basic infrastructure.

- Spaces that are already in use as pit stops by the community on ad hoc basis need to be evaluated for their suitability. If found suitable, can be officially formulated to be the NMT node.

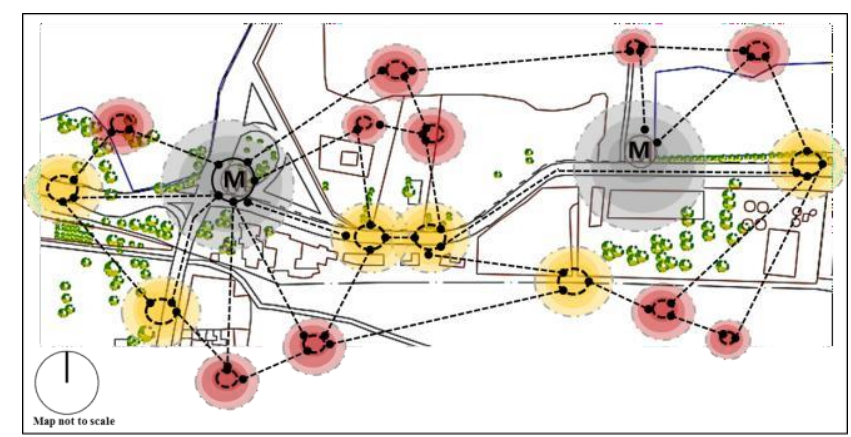

Figure 17. Location of different types of NMT nodes in and around Hebbal flyover junction (Source: Authors)

Accessibility parameters (Refer Figure 18):

- Pedestrian access: Safe, continuous, interlinked and well designed (with legible signage) pedestrian networks are of primary concern. Convenient and controlled road crossing points not only reduce commuting distances also address pedestrian-vehicular conflicts.

- Bicycle, e-scooters (docked \& dock less), e-rickshaws and shared e-bikes access: Provision of critical facilities such as safe riding networks, secured limited time parking, ICT user interface for real time updates, etc. will improve the feeder system. Additionally, Metros can have a special coach attached to the existing and proposed trains to accommodate these light weight vehicles (bicycle \& e-scooters) so that people can carry them along with special official permits and ticketing systems. 
- Intermediate Para Transit (auto rickshaws, ride hailing taxis, shared vans, etc.): Designated zones to accommodate the IPT modes that are crucial feeder systems from various parts of the neighbourhoods.

- Public bus transport: Access by public transport is determined based on the existing bus service structure, available space and specific conditions. In the long term, electric buses can replace motorised conventional buses.

- Private modes access: Access by private modes need to be restricted to drop off / pick up activities to minimise the potential conflicts and to avoid misuse of the facilities.

Branding NMT nodes through planning and design (Refer Figure 19):

- NMT nodes can be integrated and co-related with typologies of the neighbourhoods (delineated based on the characteristics of the immediate surroundings) through following strategies:

- Flexible design: NMT nodes are integral part of the built environment. Hence, they need to be unified with different locational conditions, built forms, colours, materials, etc. These nodes are to be integrated physically as well as visually with its immediate surroundings with designed provisions for enhanced access by various means of micro-mobility modes. Certain compatible uses

/ activities could be introduced.

- Visual interaction: Interactive facade \& peripheral walls as not only ICT interface for real time data/updates but can be used for displaying info graphics helping in creating awareness and educating the community with regard to greener modes of commuting. This would support economy generation as well.

- Building branding \& imageability: Building branding \& imageability through physical (static physical elements such as display boards, signage, brochures, etc.) as well as digital branding (dynamic elements such as electronic media, social media, documentaries, awareness programs, etc.).

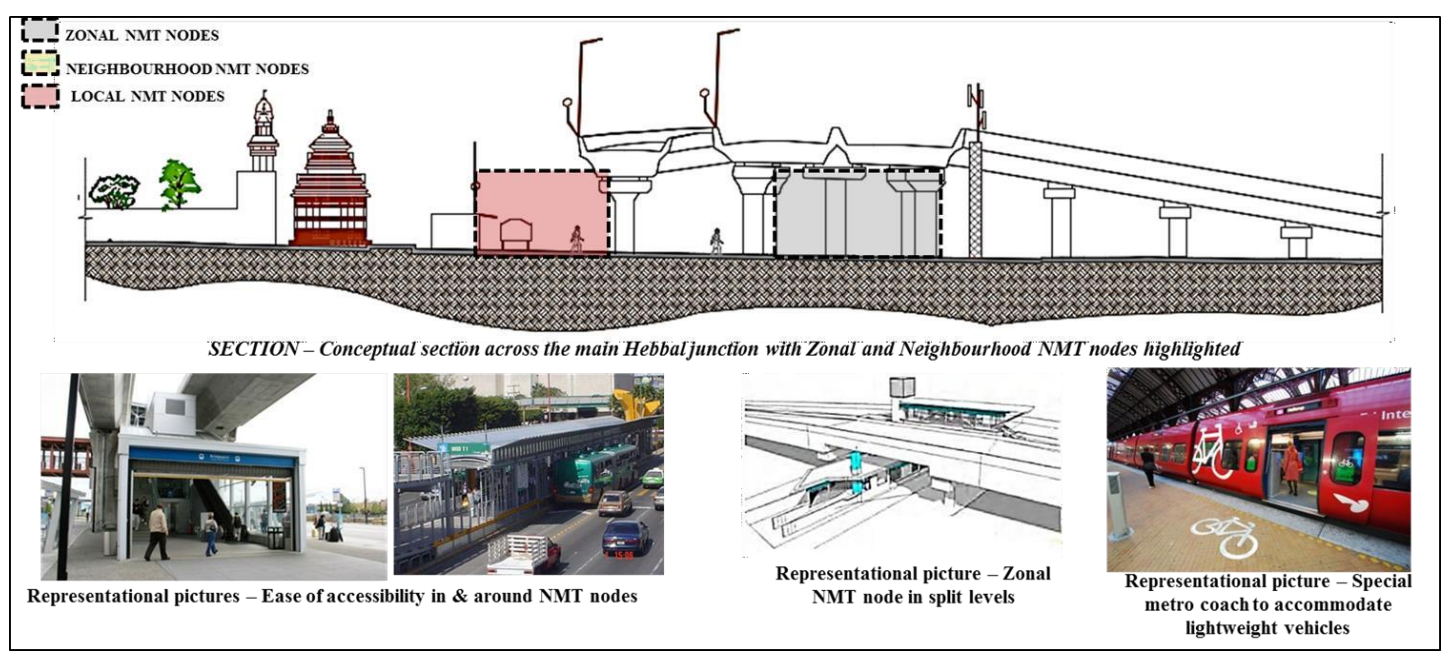

Figure 18. Conceptual section and representational pictures for Zonal and Neighbourhood NMT nodes (Source: Authors)

Recommendations for Safe Access Design (Refer Figures 20 \& 21):

- Table top crossing and raised crossing

- Surface treatment for traffic calming.

- Bus stops need to be located away from the major junctions.

- Improving pavement conditions and provision of safe and vandalism free street furniture.

- Designated IPT pick up \& drop off points. 
- Continuous pavement with bollards to restrict two-wheeler traffic.

- Shared space on secondary and tertiary roads for different modes of micro-mobility, other vehicles and parking.

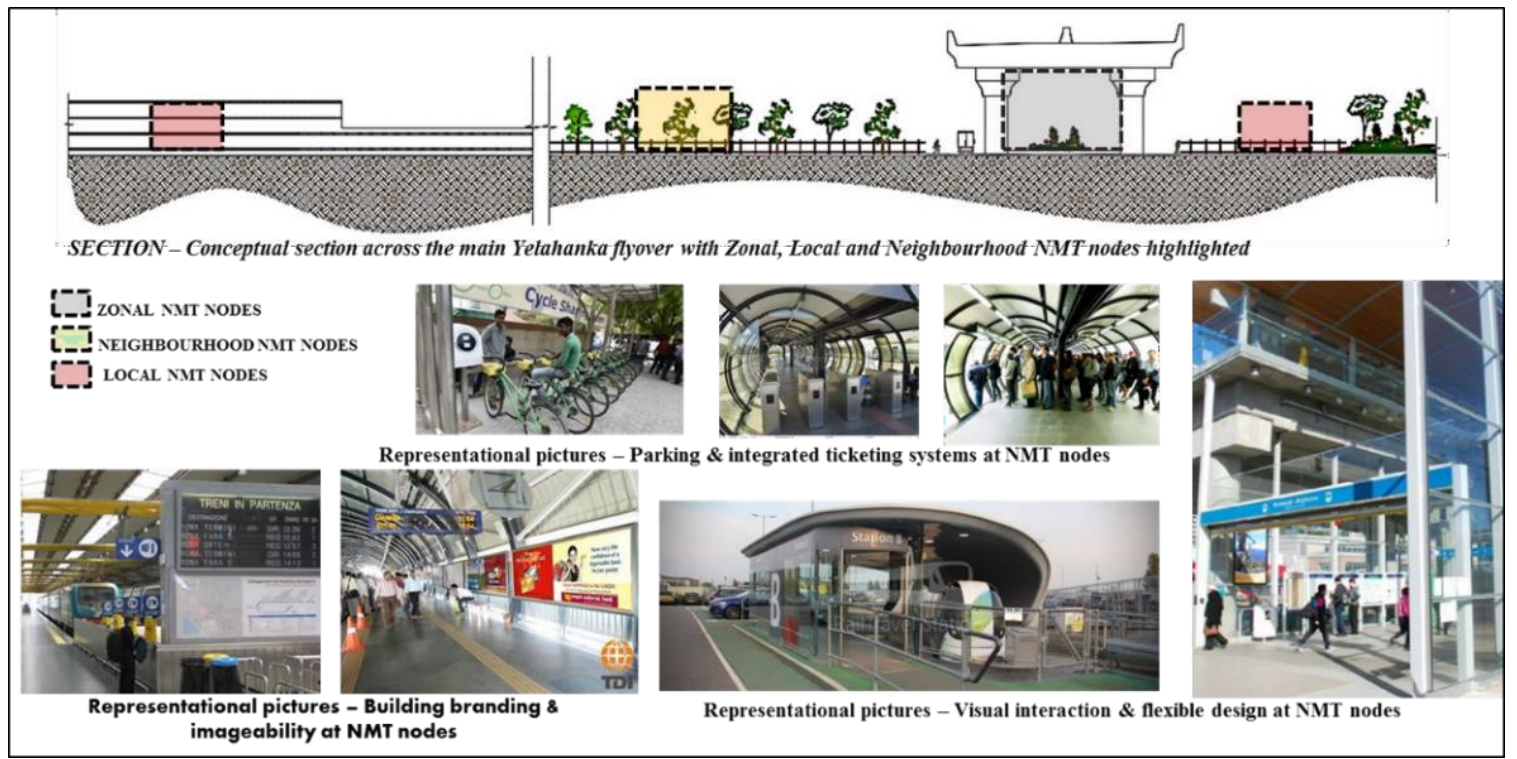

Figure 19. Conceptual section and representational pictures for Zonal, Local \& Neighbourhood NMT nodes (Source: Authors)

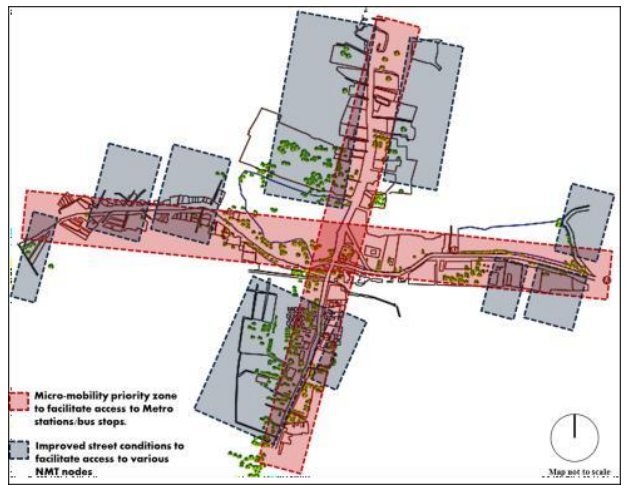

Figure 20. Map highlighting the priority zones for immediate implementation

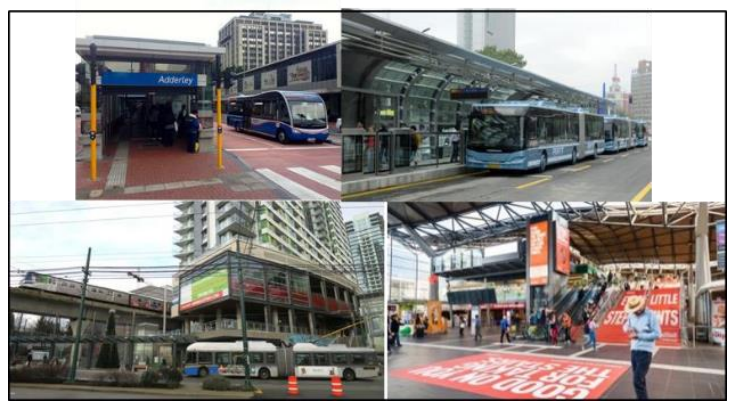

Figure 21. Representational pictures-Micro-mobility priority zones \& improved accessibility (Source: Authors)

\subsection{Regulatory Framework}

Regulatory framework for promoting micro-mobility is required to achieve city level objectives of complementing other modes and to avoid conflict with various user groups. An ad hoc, reactive approach is unsustainable and counterproductive. City should consider micromobility as an opportunity to build a more robust governance and policy framework to 
accommodate diverse mobility options underpinned by an integrated digital mobility platform that can bring together all modes of commute, better match demand \& supply to drive efficiency system wide. A fundamental aspect could be ensuring that city leaders have the data necessary for formulating informed policies. Delineating the lines of responsibility between micro-mobility providers, government and the users is the primary base for framing the regulations (Refer Table 4).

Table 4.

Regulatory framework to improve the urban mobility landscape

\begin{tabular}{lll}
\hline Sl. No. & $\begin{array}{l}\text { Regulatory } \\
\text { framework }\end{array}$ & Remarks \\
\hline 1 & Adaptive regulation & This regulation can be quickly updated as the micro-mobility market evolves. \\
& Consideration for performance based criteria (rather than fixed \& arbitrary \\
caps on fleet sizes). City should begin by articulating its transportation goals \\
and working to define metrics accordingly. \\
For ex:
\end{tabular}

Source: Authors

\subsection{Suggestions for micro-mobility service providers}

Micro-mobility service providers should be pro-active in addressing city concerns. This can range from provision of increased safety, measures to reduce vandalism, educating the riders, use of technology, appropriate measures to discourage undesirable behaviour. Providers should collaborate with officials to determine the appropriate standards, application programming interface and the nature of the data to be shared. Providers should ensure that their services promote city goals and demonstrate their value to the overall transportation network.

\section{Conclusion}

Study, analysis and schematic proposals discussed for Hebbal study area precinct highlights the benefits of well-planned and integrated micro mobility infrastructure to foster safe and reliable urban mobility options while leveraging numerous benefits to commuters of different profiles. It supports the positive augmentation of urban experiences and quality of life. Various micro-mobility options need to be integrated along with the planning of various MRTS schemes and projects (existing as well as proposed) to develop an efficient feeder system which is crucial for the successful of MRTS. Micro-mobility options provide the crucial FMC and LMC and thereby help in mitigating transit deserts. Crucial benefits and approaches for integrated micro-mobility infrastructure are summarised in the following table (Refer Table $5)$. 
Table 5.

Micro-mobility infrastructure: Benefits and Approaches

\begin{tabular}{|c|c|c|}
\hline Sl. No. & Benefits & Approaches \\
\hline & Environmental: & Hardware: \\
\hline \multirow[t]{4}{*}{1} & Improved accessibility & Appropriate infrastructure \\
\hline & Greener environment & Supporting infrastructure \\
\hline & Additional urban space & Efficient connectivity \\
\hline & Social: & Software: \\
\hline \multirow[t]{4}{*}{2} & Better public health & - $\quad$ Citizen's behaviour \\
\hline & Better exploration of city & Improved social equity \\
\hline & Better tourism opportunities & Basic safety \\
\hline & Economical: & Orgware: \\
\hline \multirow[t]{3}{*}{3} & Shared economies & Correlating strategies \\
\hline & Better economic conditions & Financing instruments \\
\hline & Cost savings & Process \& project management \\
\hline
\end{tabular}

As majority of MRTS commuters rely on para-transit modes, proactively planned and designed NMT nodes with their diverse viable options for micro-mobility would result in tangible as well as intangible societal benefits. Various innovative approaches with regard to planning and implementation mechanisms including funding coupled with technical advancements would certainly help in evolving comprehensive micro-mobility options to redefine urban mobility in order to promote holistic and sustained urban development.

\section{References}

[1]Ewing, R.H., Haliyur, P. and Page, G., 1994. Getting around a traditional city, a suburban PUD, and everything in- between. Transportation Research Record: Journal of the Transportation Research Board, 1466, pp. 53-62.

[2]Institute for Transportation and Development Policy, "Our Cities Ourselves:10 Principles for Transport in Urban Life," 2010, www.itdp.org/documents/2010-Our Cities Ourselves_Booklet.pdf

[3]Jawaharlal Nehru National Urban Renewal Mission, http://jnnurm.nic.in

[4]Lehman, M. D., Boyle, M., DeCoursey, W., \& Mix, T. (2007). Healthy \& Walkable Communities

[5]Ozbil, A. and Peponis, J., 2012 The effects of urban form on walking to transit. In: Proceedings: Eighth International Space Syntax Symposium. Santiago, PUC, 2012. 